\title{
Merging Just-in-Time (JIT) Inventory Management with Electronic Data Interchange (EDI) Impacts on the Taiwan Electronic Industry
}

\author{
Yung-I Lou', Hwei Cheng Wang2 ${ }^{2}$, Jui-Chih Chen ${ }^{3}$, Ladda Vatjanasaregagul ${ }^{4}$, Ernest P. Boger II ${ }^{5}$ \\ ${ }^{1}$ Department of Accounting, Providence University, Taichung, Taiwan \\ ${ }^{2}$ Department of Business, Management and Accounting, University of Maryland Eastern Shore, Princess Anne, \\ USA \\ ${ }^{3}$ Department of Accounting, Tamkang University, Taipei, Taiwan \\ ${ }^{4}$ School of Management Science, Sukhothai Thammathirat Open University, Nonthaburi, Thailand \\ ${ }^{5}$ Hospitality and Tourism Management Department, University of Maryland Eastern Shore, Princess Anne, USA \\ Email: yilou@pu.edu.tw, wwang@umes.edu, jcchen@mail.tku.edu.tw, vatjanas@gmail.com, \\ epboger@umes.edu
}

Received 30 June 2015; accepted 26 July 2015; published 29 July 2015

Copyright (C) 2015 by authors and Scientific Research Publishing Inc.

This work is licensed under the Creative Commons Attribution International License (CC BY).

http://creativecommons.org/licenses/by/4.0/

(c) (i) Open Access

\section{Abstract}

This paper compares the firm merging Electronic Data Interchange (EDI) with just-in-time (JIT) inventory management, to the firm with traditional inventory methods for the purpose of determining the impact of both methods on reducing inventory cost. JIT inventory management eliminates waste which includes all material, equipment, inventories and labor since JIT requires the production of just the right quantities and results in elimination of waste. (EDI) is the electronic exchange of information, documents and business transactions between computers. The information transmitted in manufacturing includes purchase orders, shipping and freight invoices, and bills of lading. There are many advantages to using EDI transaction over a traditional paper exchange environment. When the exchange of information is electronic the transactions are instantaneous. Thus, the processing and handling of paper and input of data are eliminated with no rekeying of data. Therefore, the chances of errors, time spent on auditing, and tracing errors are all significantly decreased. Additionally, the use of electronic commerce was able to cut down the lead time of purchasing and speed up inventory turnover to achieve just-in-time inventory management. Therefore, the merging of JIT with EDI has brought unprecedented benefits to users, especially with the increase in the use of international sourcing. The use of information technology to control the value chain cycle is crucial in the electronic industry, since it requires effective and efficient inventory control to speed up production and cut down inventory cost. This is an explora- 
tory research project facilitated via the case study method. Two hubs and their suppliers were investigated to reveal the use of electronic commerce in the electronic industry based on the value chain theory. The findings are the firm merging EDI with JIT will result in a higher percentage of transactions as compared with the firm using EDI with traditional inventory method. This higher percentage of transactions by EDI results in reduced supply chain inventory cost due to using EDI to reduce paper work and errors in rekeying of data, audit tracing errors, etc. Thus, the firm merging JIT with EDI results in significantly reducing supply chain inventory cost.

\section{Keywords}

Electronic Commerce, Electronic Data Interchange (EDI), Just-in-Time Inventory Management (JIT), Value Chain, Electronic Industry

\section{Introduction}

Information technologies (IT) have improved the effectiveness of communication along the value chain. Telecommunication technologies have been beneficial to integrating various functional areas within and outside firms. Specifically, Electronic data interchange (EDI) performs an important part in improving organizational communication among the industry supply chain. There is an increasing interest in the use of electronic commerce (e-commerce) such as EDI as a platform for business transactions to reduce the industry value chain length [1]-[7].

Electronic Data Interchange (EDI) is a technology which transmits business documents between the enterprises in a standard format with electronic methods. It is not only an information technology, but an effective tool for promoting competitive capability in a dynamic environment.

Compared to the traditional paper exchange environment, EDI has significantly reduced paper work, data input errors, inventories and lead times.

JIT concept is the elimination of waste and reduction of inventory costs, materials, equipment, and labor in excess of what is needed for immediate production. The JIT concept requires the production of just the right quantities at the right time.

The firm merging EDI with JIT inventory management has no paper exchanged. The replenishment orders from the firm are written to a computer file so there is no rekeying errors. So the firm that uses EDI will produce reduced inventory costs to much more favourable than firm embracing the traditional paper exchange environment.

If the firm merging EDI with JIT inventory management, EDI enables JIT firms to generate daily or even hourly shipping schedules. This type of scheduling would be accomplished with great difficulty in a traditional paper environment. Further, EDI can be used to send purchase orders and receive information as to when parts will arrive. This can significantly reduce lead time.

Although, there is much correlative literature on JIT inventory management, there is very little related to merging EDI and JIT inventory management. It is critically important to shorten the supply chain cycle for the electronic industry which has a great concern on the inventory control effectiveness. This paper compares the firm merging EDI with JIT to traditional inventory method in reducing inventory management cost by case study. Two hubs and their suppliers were investigated to reveal the use of electronic commerce in the electronic industry based on the value chain theory.

\section{Case Study}

\section{Case Company Description}

From July 1999 to December 2001, the Institute for Information Industry (III) of the Taiwanese Government has initiated a "business to business (B2B) electronic business promotion program," to support three major global IT purchaser firms (Compaq, IBM and HP) in the development of a B2B e-procurement system with their 27 Taiwanese IT suppliers. The majority of 27 Taiwanese IT suppliers of three major IT purchaser firms are Compaq's supplier. We selected the suppliers of Compaq be our objects of this study. The case study firms included two 
hubs (MITAC and INVENTEC) which are assisted by the Institute for Information Industry and their six suppliers. Figure 1 is presented the relationship among the case companies. INVENTEC has adopted just in time (JIT) purchasing. MITAC's purchasing process is traditional. X and $\mathrm{Y}$ are suppliers of MITAC and INVENTEC. M1 and M2 are suppliers of MITAC; I1 and I2 are suppliers of INVENTEC.

In this section the results of the case studies will be discussed. First an overview of the results will be given, followed by a deeper analysis of the companies, classified into hub and supplier. Beside the implication of EDI in the electronic industry, EDI impacts on the operation process and JIT inventory management are also discussed.

Table 1 exhibits the condition of implementing EDI for hub companies. The size of the two hub companies is similar, but the product and purchasing system between two firms are different. In fulfilling their customer's (e.g. COMPAQ) requirements, they adopted EDI to increase their global competitiveness. After installation of EDI, they promoted their suppliers adopting EDI to integrate the information system of their supply chain. From Table 1 we find that the INVENTEC firm merging EDI with JIT has a 95 percentage of transactions using EDI to compare with the MITAC firm using EDI with traditional inventory method indicates a significant smaller 75 percentage of transactions using EDI only. The firm with the higher percentage of transactions using EDI results in reducing supply chain inventory costs since EDI has many advantage over a traditional paper exchange environment. These include, no paper work, rekeying errors, reducing auditing time and tracing errors, and faster inventory turnover to reduce inventory management cost. Thus, we conclude the INVENTEC firm merging EDI with JIT has lower supply chain inventory costs.

EDI can be added on to an existing computer system and hooked up directly to a supplier. The use of EDI and JIT by many manufacturers has forced their suppliers to utilize the same systems since by using EDI in dealing with suppliers, they are able to notify suppliers of last minute changes in schedules and over shipping conditions. The firm merging EDI with JIT inventory management has no paper exchanged. The replenishment orders from the firm are written to a computer file and forwarded to a supplier's computer. After the supplier receives the order, it electronically transmits packing information to the warehouse of manufacturer and shipper. The supplier produces the invoice in the form of a computer file and sends it to the manufacturer. The supplier and manufacturer can easily track this shipping process. Table 2 presents the Condition for implementing EDI with supplier companies. From Table 2, we find the INVENTEC firm merging EDI with JIT has more suppliers implementing EDI as compared with the MITAC firm utilizing the traditional inventory method.

\section{Conclusions}

The researchers compared a firm merging EDI with JIT inventory management to a firm with traditional inventory methods to probe the impact of both inventory methods on reducing inventory cost.

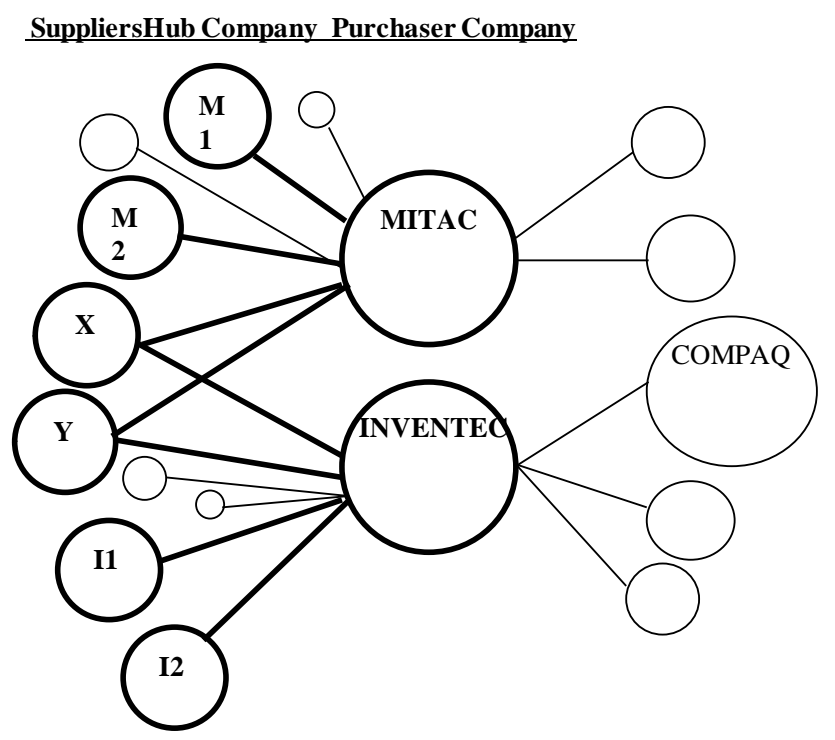

Figure 1. The relationship among the case companies. 
Table 1. The Condition about implementing EDI for hub companies.

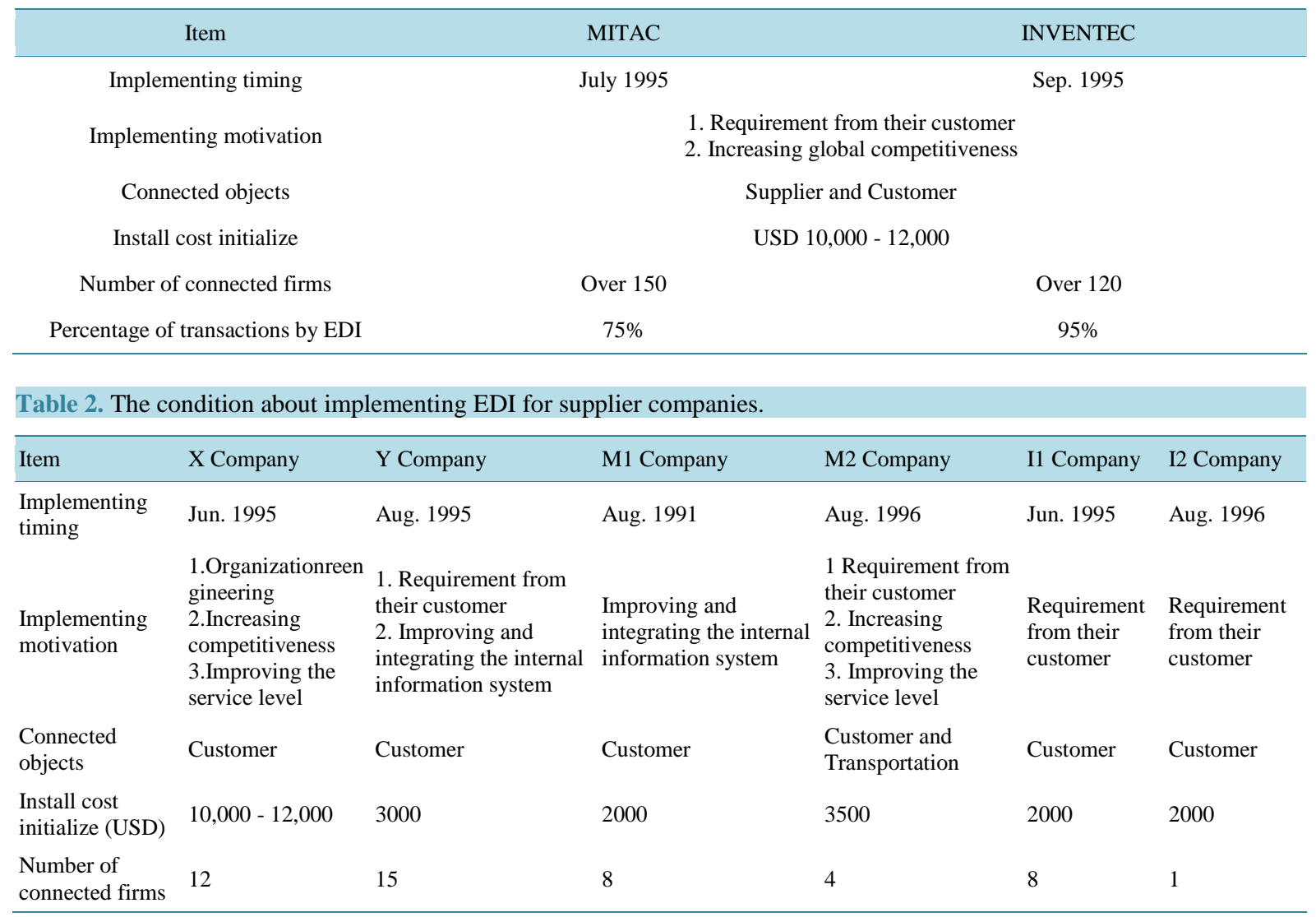

JIT inventory management eliminates waste which includes all material, equipment, inventories and labor. Since JIT requires the production of just the right quantities at just the right time, the natural product is a waste elimination.

Electronic Data Interchange (EDI) is the electronic exchange of information, documents and business transactions between computers. When the exchange of information is electronic, the transactions are instantaneous. Thus, the processing and handling of paper and input of data are eliminated. There is no rekeying of data, therefore the chances of errors, time spent on auditing, and tracing errors are significantly decreased. Therefore, the merging of JIT with EDI has brought unprecedented benefits to users, especially with the increase in the use of international sourcing.

Our findings are that the firm merging EDI with JIT will result in a higher percentage of transactions compared with the firm using EDI with traditional inventory method. This higher percentage of transactions by EDI will result in reduce supply chain inventory cost due to using EDI to reduce paper work and errors in rekeying of data, audit tracing errors, etc. Thus, the firm with merging JIT and EDI significantly results in reducing supply chain inventory costs. Additionally, we found the firm merging EDI with JIT has more suppliers implementing EDI to compare with the firm using traditional inventory method since the use of EDI with JIT by manufacturers has forced their suppliers to utilize the same systems. JIT systems can be electronically linked to the suppliers and shorten materials delivered before they are needed for processing to significantly reduce holding inventory cost.

\section{References}

[1] Angeles, R. and Nath, R. (2000) The Importance of Congruence in Implementing Electronic Data Interchange Systems. Supply Chain Management: An International Journal, 5, 198-205.

[2] Angeles, R., Nath, R. and Hendon, D.W. (1998) An Empirical Investigation of the Level of Electronic Data Interchange (EDI) Implementation and Its Ability to Predict EDI System Success Implementation Factors. International 
Journal of Physical Distribution \& Logistics Management, 28, 773-793. http://dx.doi.org/10.1108/09600039810248163

[3] Attaran, M. (2001) The Coming Age of Online Procurement. Industrial Management \& Data Systems, 101, 177-180. http://dx.doi.org/10.1108/02635570110390080

[4] Bhatt, G.D. (2001) Business Process Improvement through Electronic Data Interchange (EDI) Systems: An Empirical Study. Supply Chain Management: An International Journal, 6, 60-73.

[5] Dhillon, G. and Caldeira, M. (2000) Interpreting the Adoption and Use of EDI in the Portuguese Clothing and Textile Industry. Information Management \& Computer Security, 8, 184-189. http://dx.doi.org/10.1108/09685220010344934

[6] Hsieh, C.T., Yang, H. and Lin, B. (2002) Roles of Knowledge Management in Online Procurement Systems. Industrial Management \& Data Systems, 102, 365-370. http://dx.doi.org/10.1108/02635570210439454

[7] Kumar, K. and van Dissel, H.G. (1996) Sustainable Collaboration: Managing Conflict and Cooperation Interorganizational Systems? MIS Quarterly, 20, 279-300. http://dx.doi.org/10.2307/249657 